\title{
Erratum to: Specific stressors in endonasal skull base surgery with and without navigation
}

\author{
K. Stelter $\cdot$ M. N. Theodoraki $\cdot$ S. Becker $\cdot$ \\ V. Tsekmistrenko $\cdot$ B. Olzowy $\cdot$ G. Ledderose
}

Published online: 23 January 2015

(c) Springer-Verlag Berlin Heidelberg 2015

\section{Erratum to: Eur Arch Otorhinolaryngol \\ DOI 10.1007/s00405-014-3154-8}

The original article was published with the incorrect author group. The correct author group is provided below:

K. Stelter, M. N. Theodoraki, S. Becker, V. Tsekmistrenko, B. Olzowy, G. Ledderose

The original article has been updated with the new author group.

In contrast to the indication in the article, no team of the Professional Group for Work Psychology in Berlin was involved in the work.
In contrast to the statement in the article that the spectral analysis of the interbeat intervals has been implemented with the programme CARSPAN (developed by B. Mulder, Groningen) [14] and the support of the Professional Group for Organisational Psychology in Berlin, the latter was not involved in the study.

The original article has been updated accordingly.

The online version of the original article can be found under doi:10.1007/s00405-014-3154-8.

K. Stelter · S. Becker · V. Tsekmistrenko - G. Ledderose Department of Otorhinolaryngology, Ludwig Maximilians University, Munich, Germany

K. Stelter $(\bowtie)$

Private Practice, ENT-Centre Mangfall-Inn, Rosenheim 83022,

Germany

e-mail: klaus.stelter@med.uni-muenchen.de

M. N. Theodoraki

Department of Otorhinolaryngology, University of Ulm,

Ulm, Germany

B. Olzowy

Department of Otorhinolaryngology, Otto Körner,

University of Rostock, Rostock, Germany 